\title{
Influence of Inertia and Low Active Mineral Admixture on Strength and Microstructure of Cement-Based Materials
}

\author{
Meijuan Rao, ${ }^{1,2}$ Wan Tang, ${ }^{3}$ Wei Zhou, ${ }^{3}$ Yaning Kong, ${ }^{3}$ and Shuhua Liu ${ }^{3}$ \\ ${ }^{1}$ Changjiang River Scientific Research Institute, Wuhan 430010, China \\ ${ }^{2}$ State Key Laboratory of Silicate Materials for Architectures, Wuhan University of Technology, Wuhan 430070, China \\ ${ }^{3}$ State Key Laboratory of Water Resources and Hydropower Engineering Science, Wuhan University, Wuhan 430072, China
}

Correspondence should be addressed to Shuhua Liu; shliu@whu.edu.cn

Received 10 May 2016; Revised 1 July 2016; Accepted 5 July 2016

Academic Editor: Ana S. Guimarães

Copyright (C) 2016 Meijuan Rao et al. This is an open access article distributed under the Creative Commons Attribution License, which permits unrestricted use, distribution, and reproduction in any medium, provided the original work is properly cited.

\begin{abstract}
Cement-based materials were investigated by comparing the strength and microstructure of pastes and mortar containing limestone powder or low quality fly ash. The compressive strength of the mortar at 28 and $90 \mathrm{~d}$ was examined whose microstructures were characterized by X-ray diffraction (XRD), scanning electron microscopy (SEM), thermogravimetric analysis, and differential thermal analysis (TG-DTA). The results indicated that the strength of mortar decreased with increasing mineral admixtures. The limestone powder mainly acted as inert filler and hardly took part in the chemical reaction. Low quality fly ash may accelerate the formation of hydration products in samples with more chemically bonded water. This further resulted in a higher degree of cement hydration and denser microstructure, while the overall heat of hydration was reduced. At the early stage of hydration, low quality fly ash can be considered as an inert material whereas its reactivity at the later stage became high, especially for ground low quality fly ash.
\end{abstract}

\section{Introduction}

Cement is widely used in the production of concrete with its annual consumption close to 2 billion tons [1-3]. The production of cement itself however is quite energy-intensive and responsible for large quantities of $\mathrm{CO}_{2}$ emissions. In addition, the high amount of alkali in cement might cause cracks in the structure of concrete [4]. As one of the solutions to these, nowadays many mineral admixtures have been used as supplementary cementitious materials (SCMs) $[5,6]$ to reduce the amount of cement clinker, with other excellent properties such as reduced heat of hydration and improved durability of concrete.

Mineral admixtures can be divided into cementitious materials, pozzolanic active materials, and inert materials according to their chemical activities [7]. Some studies have shown that the inert mineral admixture can enhance the properties of concrete in terms of strength, frost resistance, and so forth [8-11]. This is mainly due to the dilution effect of the inert mineral admixture on cement [11]. It has been reported that equivalent amount of low active or inert mineral admixture exhibited no difference in the early hydration of cementitious materials $[12,13]$. Recently, limestone powder has been applied widely in construction engineering as a new type of concrete admixture [14-16]. The particle size distribution and fineness of limestone powder are similar to those of fly ash, both of which have physical activity, morphological effect, and filling effect. The use of limestone powder as admixture in concrete leads to a better accumulation effect in cement particle skeleton and offers crystalline nucleus to the formation of calcium hydroxide $(\mathrm{CH})$ and calcium silicate hydrate (C-S-H) gel. These synergistic effects can accelerate the process of cement hydration. It is traditionally believed that limestone powder is an inert admixture with high fineness which may be applied in concrete to make up composite cementitious material system that gives full play to its microaggregate effect [17-19]. Fly ash is used in concrete in the building material industry, construction engineering, and road engineering accounts for about $90 \%$ of its overall use $[20,21]$. Although the progress in fly ash utilization is at the forefront compared to some developed countries, the utilization level is still very low. Research in fly ash is mainly 
TABLE 1: Chemical composition of cement, low quality fly ash, and limestone powder/mass, $\%$.

\begin{tabular}{lccccccccc}
\hline Compositions & $\mathrm{SiO}_{2}$ & $\mathrm{Fe}_{2} \mathrm{O}_{3}$ & $\mathrm{Al}_{2} \mathrm{O}_{3}$ & $\mathrm{CaO}$ & $\mathrm{MgO}$ & $\mathrm{K}_{2} \mathrm{O}$ & $\mathrm{Na}_{2} \mathrm{O}$ & $\mathrm{SO}_{3}$ & $\mathrm{LOI}$ \\
\hline Cement & 23.61 & 3.44 & 4.06 & 59.59 & 2.51 & 0.86 & 0.19 & - & 3.00 \\
Low quality FA & 53.41 & 4.28 & 25.79 & 2.60 & 2.79 & 1.38 & 0.42 & 0.3 & 3.67 \\
Limestone powder & 1.79 & 0.35 & 0.56 & 54.69 & 0.40 & 0.14 & - & 0.03 & 41.93 \\
\hline
\end{tabular}

TABle 2: Physical properties of mineral admixtures.

\begin{tabular}{lcccc}
\hline Test item & Residue on sieve of $45 \mu \mathrm{m} / \%$ & Water requirement $/ \%$ & Specific area $/ \mathrm{m}^{2} \cdot \mathrm{kg}^{-1}$ & Density $/ \mathrm{kg} \cdot \mathrm{m}^{-3}$ \\
\hline Cement & - & - & 437 & 780 \\
Limestone powder & 16.0 & 98.0 & 270 & 2670 \\
Raw fly ash & 49.8 & 99.6 & 790 & 1880 \\
Ground fly ash & 19.7 & 100.4 & 794 & 2340 \\
\hline
\end{tabular}

focused on its physical and chemical properties, but few studies have reported low quality fly ash. In order to promote further use of fly ash, it is therefore critical to say something here about the significance of this work.

In this paper, a comparative system was for the first time established to assess the impacts of limestone powder as an inertia mineral admixture and fly ash as a low active mineral admixture on the strength and microstructure of cementbased materials. This is of great significance in improving the level of low quality fly ash utilization, thereby conserving resources and protecting the environment.

\section{Experimental}

2.1. Raw Materials. Ordinary Portland cement P.O 42.5 is supplied by Huaxin Cement Plant. Low quality fly ash is supplied by Guanyinyan Hydropower Project. Table 1 shows the chemical compositions of the cement, fly ash, and limestone powder determined by X-ray Fluorescence (XRF).

Figure 1 is the particle morphology of raw ash and ground ash. The raw low quality fly ash particle is coarse and irregular and its sieve residue of $45 \mu \mathrm{m}$ reaches as high as $49.8 \%$. The particle microstructure was significantly improved to be smaller and uniform after grinding. Table 2 presents the physical properties of the admixtures. Water demand for the raw fly ash is so high, because there is less free water in raw ash; on the other hand, there are more coarse pore carbon particle in raw ash.

Particle sizes of cement, limestone, raw ash, and ground fly ash were analyzed by OMEC lazer particle size analyzer LS-C (III) and Figure 2 shows the cumulative diameter percentage and the differential curve. It can be seen that the particle size distributions of limestone powder and cement were very similar with the former being slightly smaller.

2.2. Testing Methods. The quantitative analysis of the influence of limestone powder and low quality fly ash on the strength and microstructure of cement-based materials was based on the comparison of pure cement paste with the content of $20 \%, 40 \%$, and $60 \%$. Water-binder ratio is 0.5 . Table 3 lists the paste mix proportions.
TABLE 3: Mix proportion of composite cementitious materials/mass, $\%$.

\begin{tabular}{lcccc}
\hline Sample & Cement & $\begin{array}{c}\text { Limestone } \\
\text { powder }\end{array}$ & Raw fly ash & Ground fly ash \\
\hline C & 100 & - & - & - \\
L2 & 80 & 20 & - & - \\
L4 & 60 & 40 & - & - \\
L6 & 40 & 60 & - & - \\
R2 & 80 & - & 20 & - \\
R4 & 60 & - & 40 & - \\
R6 & 40 & - & 60 & - \\
G2 & 80 & - & - & 20 \\
G4 & 60 & - & - & 40 \\
G6 & 40 & - & - & 60 \\
\hline
\end{tabular}

Paste specimens with $40 \mathrm{~mm} \times 40 \mathrm{~mm} \times 40 \mathrm{~mm}$ dimensions and a 0.4 -water-binder ratio (W/C) were molded and cured with higher than $90 \%$ relative humidity and $20 \pm 2^{\circ} \mathrm{C}$ temperature until the stipulated age of $3,7,28$, and 90 days. Determining the compressive strength of mortar specimens of different ages was conducted by WAY-2000 (i.e., a battery solution type compressive testing machine). Clean, bean-size samples were taken from the center of broken specimens and packed into ampere bottles filled up with absolute ethanol to terminate the hydration process before the XRD, TG-DTA, and SEM microcosmic analysis. Sample pieces were held in a dry environment at $60^{\circ} \mathrm{C}$ for 2 or 3 hours before SEM tests. The other samples were ground in an agate mortar and dried at $60^{\circ} \mathrm{C}$ for 2 hours to reduce carbonation before the XRD test and then dried in vacuum condition before the TG-DTA test.

The XRD analysis was made by X-ray diffraction, using a copper target and a continuous scan machine produced by RIGAKU, a Japanese company. The TG-DTA in an $\mathrm{N} 2$-atmosphere up to a temperature of $1200^{\circ} \mathrm{C}$ adopted the diamond TG/DTA analysis produced by Perkin Elmer Instruments Plant, and the morphology of the products was investigated using a scanning electron microscopy (JSM5610LV, Japan). 

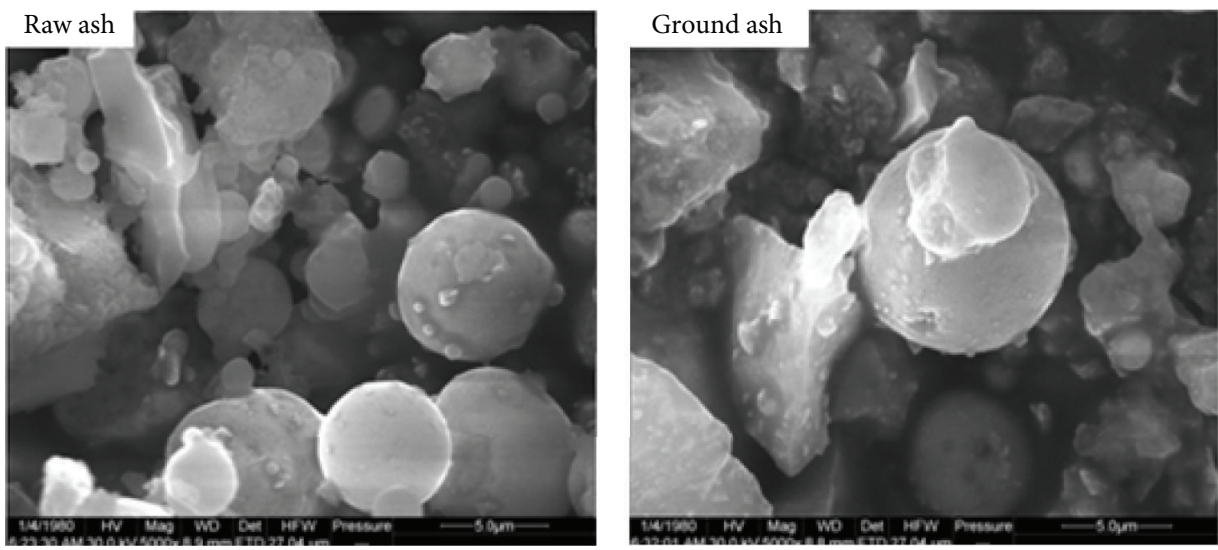

FIGURE 1: Particle morphology of raw ash and ground ash.

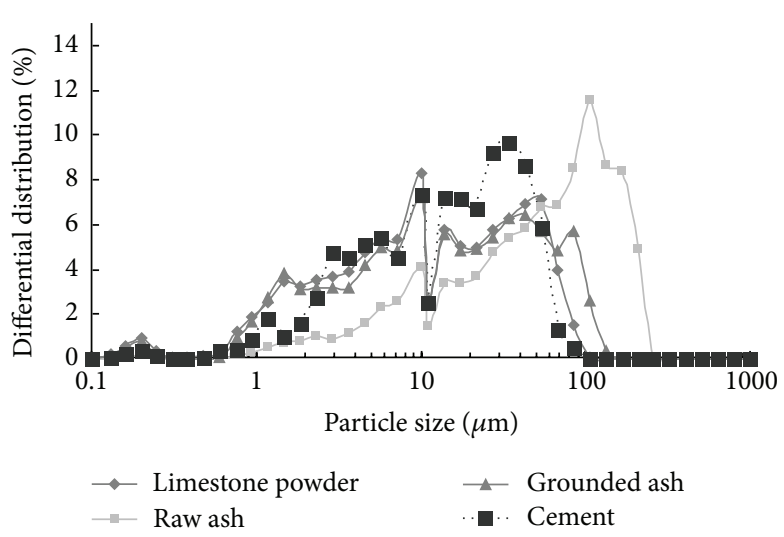

(a)

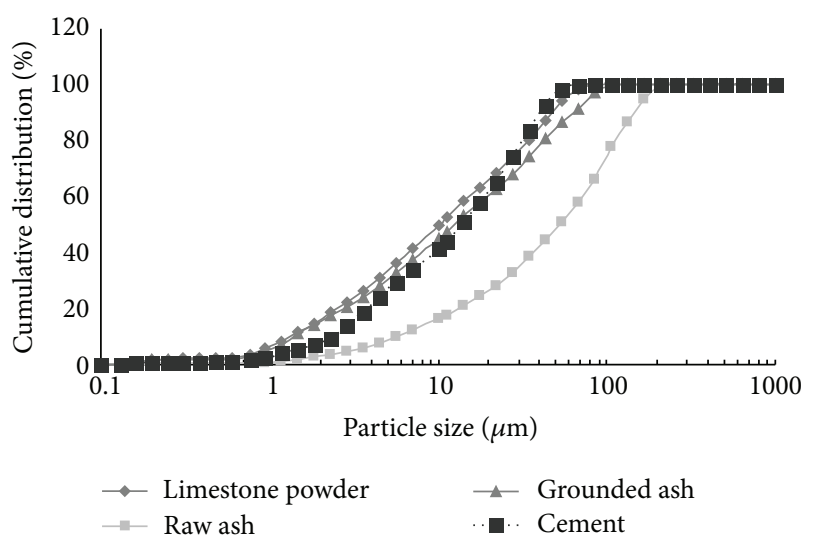

(b)

Figure 2: (a) Differential and (b) cumulative particle size distribution of the cementitious materials.

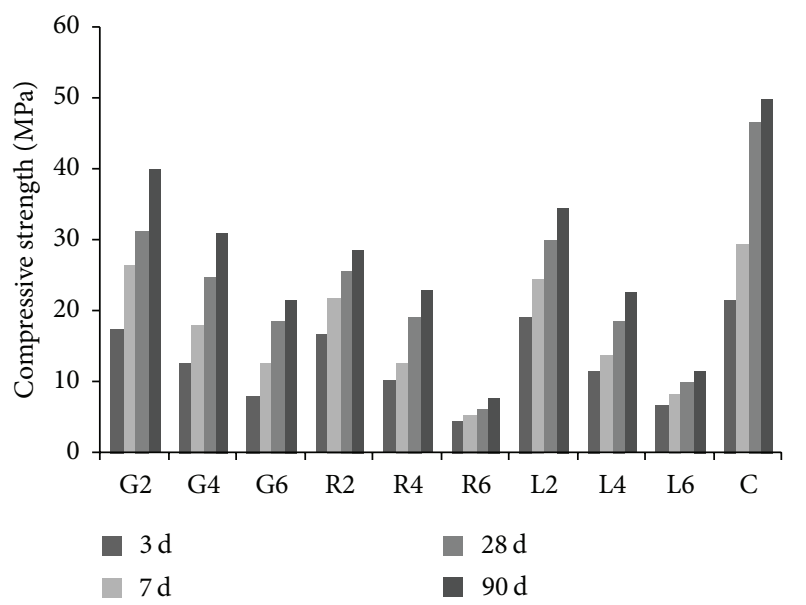

FIGURE 3: Compressive strength of mortars with water-binder ratio of 0.5 .

\section{Results and Discussion}

3.1. Strength. Figures 3 and 4 present the compressive strength of mortar at different water-binder ratios of 0.3 and 0.5 . The figures showed that the strength of mortar decreased with increasing incorporation of admixture at the same water-binder ratio. The mortar containing low content of limestone powder showed higher compressive strength than that containing ground fly ash at the early stage of hydration. However, with the onset of hydration, the strength of the mortar containing ground fly ash improved rapidly and exceeded the one with limestone at the later age, which may be linked to the higher pozzolanic activity of fly ash at the later period.

The water-binder ratio had little influence on the strength developing law of mortar containing limestone powder or ground fly ash. Therefore, reducing the water-binder ratio could significantly improve the strength of mortar specimen containing high content of ground fly ash or low content (20\%) raw fly ash to higher strength than those containing the same content of limestone powder.

3.2. Hydration Heat Evolution Process. Figure 5 shows the hydration heat produced and the rate of heat evolution for the four selected mixtures within the first $72 \mathrm{~h}$. The hydration heat curves indicated that the influence of incorporating different admixtures in the composite cementitious materials varied the hydration heat. The addition of fly ash exhibited little effect on the five stages of cement hydration but reduced 


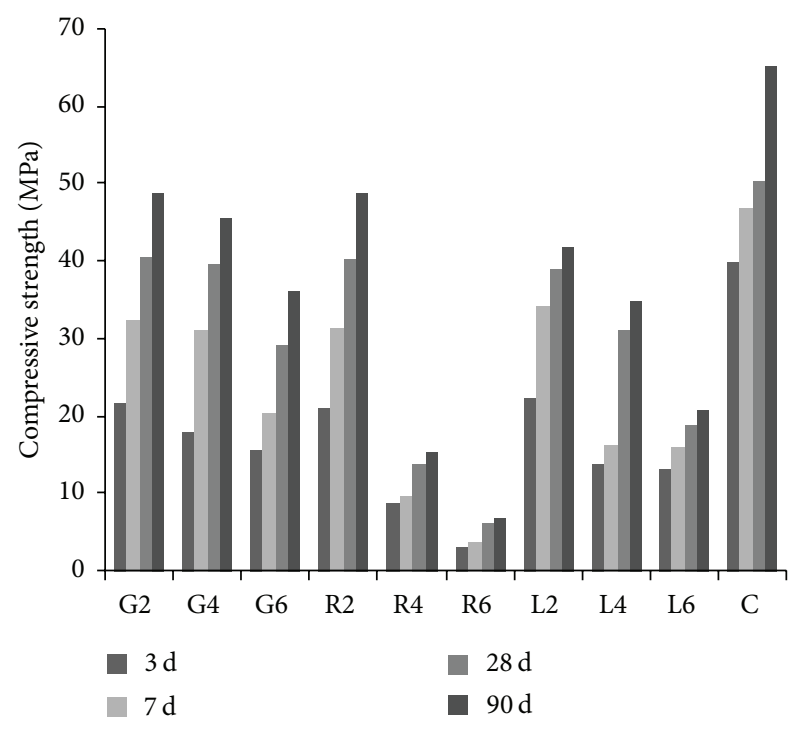

FIGURE 4: Compressive strength of mortars with water-binder ratio of 0.3 .

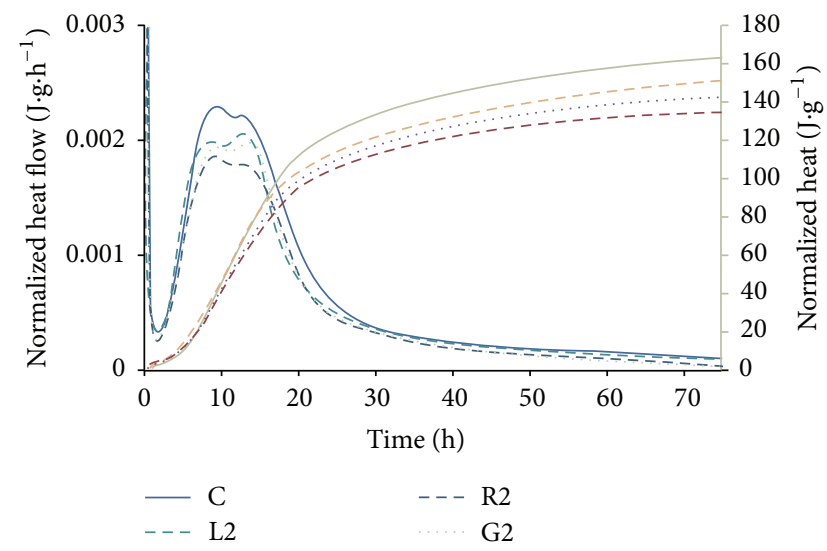

FIGURE 5: Hydration heat and rate of the cementitious materials.

the hydration rate and the total heat compared to those of the pastes $C$. The third exothermic peak, caused by the conversion of AFt to AFm as a result of the consumption of gypsum, was much higher than the second one in paste G2 whereas the opposite response was observed in paste R2. This suggested that fine-grinding leads to a quicker hydration reaction and both raw ash and ground ash as mineral admixtures reduce the heat of hydration which is beneficial to mass concrete construction. The rate of heat evolution of pastes L2 exceeded that of G2 after the induction period but became lower during the deceleration period. It is proposed that the transformation from ettringite to a more steady monocarbon aluminate contributed to the third exothermic peak.

For further analysis, Figure 6 presents a plot of the induction period against the acceleration period in the hydration process. The addition of fly ash prolonged the induction period but shortened the acceleration period compared with pastes $\mathrm{C}$, which demonstrated that fly ash had little effect

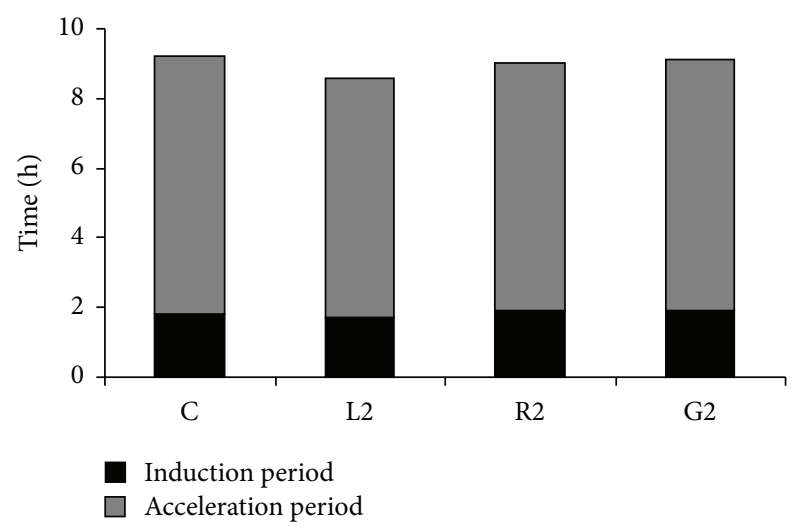

FIGURE 6: Induction period and acceleration period of the cementitious materials.

on the appearance of the second exothermic peak. There are two reasons for the extension of the induction period. On one hand, the increase of effective water reduced the concentration of $\mathrm{Ca}^{2+}$ in the pore solution and extended the induction period by increasing the time required for $\mathrm{Ca}^{2+}$ saturation. On the other hand, ground fly ash sphere particles may adsorb $\mathrm{Ca}^{2+}$ in solution, which inhibited the increase of $\mathrm{Ca}^{2+}$ concentration through adsorption in the first few hours. This also delayed the crystallization nucleation of $\mathrm{CH}$ and $\mathrm{C}-\mathrm{S}-\mathrm{H}$ and accordingly cements hydration. In the accelerated phase, more water came into contact with the new exposed surface and accelerates cement hydration because of the increasing effective water. In summary, the nucleation effect of the ground fly ash may also accelerate cement hydration.

The difference between pure cement and cement-based materials is that the cement-based material containing limestone powder had three special points. These special points included a shortened induction period, an accelerated period, and a significantly higher third exothermic peak at around 13 hours. It accounted for the assertion that limestone powder does not take part in hydration due to its inertia but acts as a filler and contributes to the nucleation of $\mathrm{C}_{3} \mathrm{~S}$ and $\mathrm{C}_{2} \mathrm{~S}$ [22].

\subsection{Microstructure}

3.3.1. Hydration Products. Figures 7 and 8 show the XRD patterns of the hydration products of the selected pastes at 7 and $90 \mathrm{~d}$, respectively. The main peaks in pastes $\mathrm{C}$ are those of calcium hydroxide $(\mathrm{CH})$ and ettringite. The peaks of mullite $(\mathrm{M})$ and quartz $(\mathrm{Q})$ in the specimen containing fly ash are clearly evident, indicating that fly ash did not influence the types of cement hydration products. This was because the main chemical composition and component were the same. In addition to the noticeable diffraction peaks of calcium carbonate, there were also obvious single carbon calcium aluminate diffraction peaks in pastes L2. This was due to the calcium carbonate which reacted with $\mathrm{C}_{3} \mathrm{~A}$ to produce single carbon hydrated calcium aluminate as the main ingredient of limestone powder. 


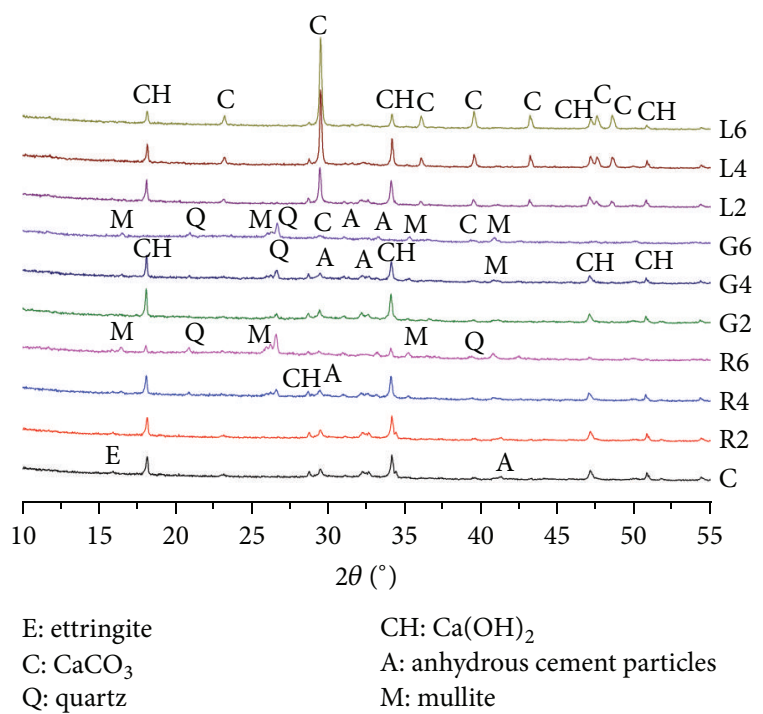

FIGURE 7: XRD patterns of specimens at $7 \mathrm{~d}$.

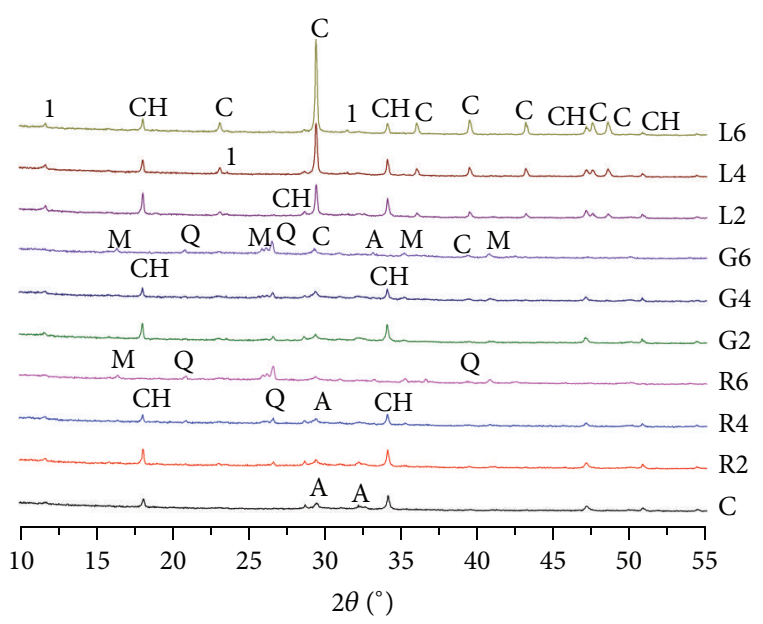
M: mullite
Q: quartz
(1) $\mathrm{C}_{3} \mathrm{~A} \cdot \mathrm{CaCO}_{3} \cdot 11 \mathrm{H}_{2} \mathrm{O}$
A: anhydrous cement particles
$\mathrm{CH}: \mathrm{Ca}(\mathrm{OH})_{2}$
C: $\mathrm{CaCO}_{3}$

FIGURE 8: XRD patterns of specimens at $90 \mathrm{~d}$.

Figures 9 and 10 also showed that the $\mathrm{CH}$ content in pastes $\mathrm{R} 2$ was lower at $90 \mathrm{~d}$, indicating that the raw ash consumed some $\mathrm{CH}$ at $7 \mathrm{~d}$. As for pastes $\mathrm{G} 2$, grinding may promote the activity, which made much higher consumption of $\mathrm{CH}$ at the secondary hydration, causing $\mathrm{CH}$ content at $90 \mathrm{~d}$ to be far less than that at $7 \mathrm{~d}$. In addition, due to the consumption of cement clinker with hydration process, the characteristic peak of clinker was also reduced, which indicated exactly that fly ash exhibited a filling effect in promoting the hydration of cement to form $\mathrm{CH}$. However, the ground one worked better. The $\mathrm{CH}$ content in pastes R2 was slightly higher at $90 \mathrm{~d}$, suggesting that the raw ash was less active than the ground ash for the coarse particle, contributed to a relatively loose mortar structure. The strength of pastes R2 was lower.

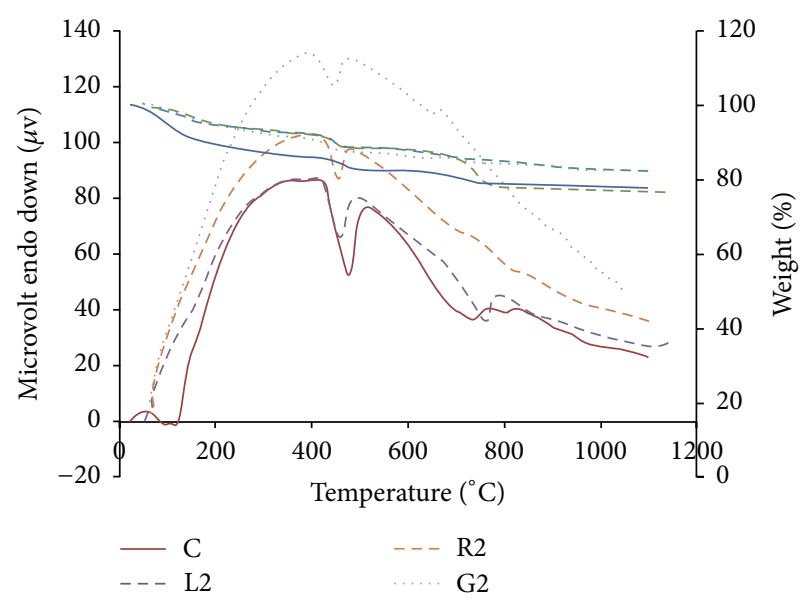

FIGURE 9: TG-DTA curves of C, L2, R2, and G2 at $7 \mathrm{~d}$.

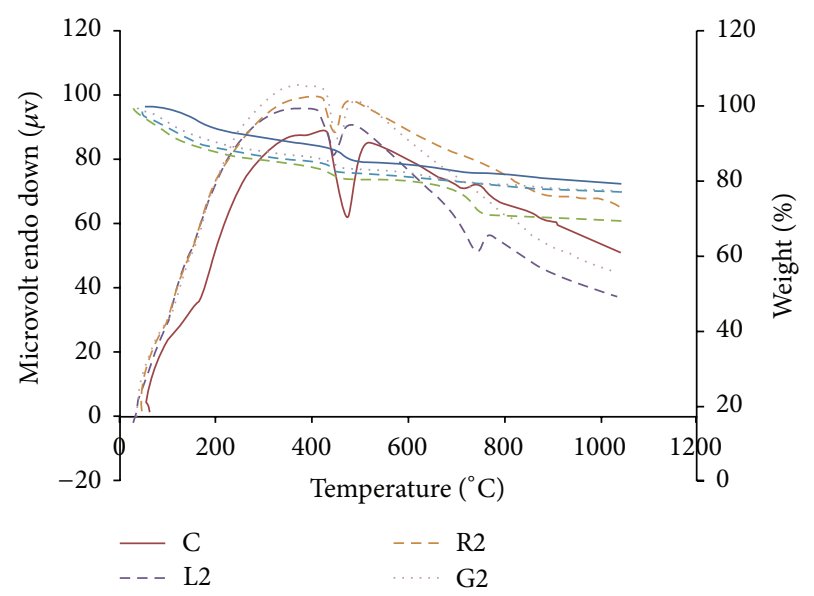

FIgURE 10: TG-DTA curves of C, L2, R2, and G2 at $90 \mathrm{~d}$.

When the content of fly ash was up to $40 \%$, the calcium hydroxide content was lower than that of the cement paste at the age of $90 \mathrm{~d}$ and was significantly lower than that of the sample at the age of $7 \mathrm{~d}$. As a result, the early filling effect of fly ash promoted the cement hydration; however, the late pozzolanic reaction was gradual and consumed part of the calcium hydroxide. Comparing each group with admixture content of $20 \%$, the amount of calcium hydroxide decreased at the age of $90 \mathrm{~d}$ for two main reasons. The first reason was the relative decrease in the cement content and the amount of calcium hydroxide produced. The other reason was that the pozzolanic activity of ash was more evident with increasing ash. Moreover, from the slurry map of ash mixed with raw fly ash, the content of calcium hydroxide changed similarly compared with that of ground fly ash indicating that the raw fly ash had pozzolanic activity.

When the content of fly ash was up to $60 \%$ (high volume), the diffraction peak of calcium hydroxide was significantly lower than that of the pure cement hydration at the age of $7 \mathrm{~d}$ and $90 \mathrm{~d}$, respectively. The content of $\mathrm{CH}$ was less or even disappeared at the age of $90 \mathrm{~d}$ compared with that at the age of $7 \mathrm{~d}$ because the $\mathrm{CH}$ content produced by the cement 
TABLE 4: Nonevaporating water content and hydration degree/mass, $\%$.

\begin{tabular}{lcc}
\hline Sample & \multicolumn{2}{c}{ Nonevaporating water } \\
\hline C & $7 \mathrm{~d}$ & $90 \mathrm{~d}$ \\
L2 & 13.88 & 16.62 \\
R2 & 11.5 & 12.02 \\
G2 & 12.34 & 13.35 \\
L4 & 12.91 & 14.89 \\
R4 & 8.51 & 10.26 \\
G4 & 9.33 & 11.53 \\
L6 & 11.01 & 12.31 \\
R6 & 2.89 & 3.42 \\
G6 & 3.35 & 4.83 \\
\hline
\end{tabular}

hydration failed to meet the needs of the pozzolanic reaction of ash.

The significant differences between the pastes fully demonstrated that limestone powder promoted cement hydration with growth in age. Raw ash exhibited a filling effect in promoting cement hydration for its coarse particle and low activity. Grinding improved the activity of fly ash and was also conductive to its pozzolanic activity.

The content of nonevaporable water mainly depends on the quantity of hydration products, which relates to the hydration degree. Therefore, the content of nonevaporating water can be used to characterize the degree of cement hydration. The content of nonevaporating water is calculated as follows:

$$
\begin{aligned}
H & =w_{105}-w_{1050}-\gamma, \\
\gamma & =p_{f} r_{f}+p_{c} r_{c},
\end{aligned}
$$

where $w$ is the mass fraction measured by TG at corresponding temperature, $\gamma$ is the loss of ignition, $p_{f}$ is the mass fraction of admixture, $p_{c}$ is the mass fraction of cement and, $r_{f}$ and $r_{c}$ are the corresponding losses of ignition. Table 4 summarizes the results obtained from Figures 9 and 10.

Fly ash carries out the secondary pozzolanic reaction and participates in the hydration and excitation of calcium hydroxide as hydration product of cement clinker, contributing to strength. So the amount of $\mathrm{CH}$ consumed can indirectly reflect the hydration degree and the TG method can accurately determine the content of $\mathrm{CH}$. The calcium hydroxide content is calculated according to the following equation and results given in Table 5:

$$
\mathrm{CH}=\left(w_{\text {initial }}-w_{\text {finish }}\right) \cdot \frac{74}{18} .
$$

Table 5 lists the $\mathrm{CH}$ content calculated according to TG curves.

At $7 \mathrm{~d}$, the nonevaporating water in the group with admixture incorporated was lower than that in group C, which showed that admixtures promoted cement hydration to varying degrees. The nonevaporable water content of
TABLE 5: CH content of the hydration products/mass, $\%$.

\begin{tabular}{lcc}
\hline Sample & Seven days & 90 days \\
\hline C & 13.46 & 16.39 \\
L2 & 13.36 & 14.81 \\
R2 & 12.53 & 11.35 \\
G2 & 12.18 & 11.04 \\
L4 & 12.01 & 10.88 \\
R4 & 11.98 & 10.65 \\
G4 & 9.59 & 9.37 \\
L6 & 4.13 & 3.99 \\
R6 & 2.92 & 0.85 \\
G6 & 1.23 & 0.00 \\
\hline
\end{tabular}

groups G2 and R2 did not appear to be much different from each other and was just slightly higher than that of group L2. This was due to the low content of cement and the higher activity of G2 than that of R2, which accounted for the large number of nonevaporating hydrogels. In contrast, the limestone powder only promoted cement hydration. At $90 \mathrm{~d}$, the content of nonevaporating water of each group differed a lot and increased with age. The content of nonevaporating water of group L2 remained stable and low, which means that the later products of L2 contained less bounded water. Meanwhile, the nonevaporating water of the pastes containing fly increased significantly, indicating that hydration products between 7 and $90 \mathrm{~d}$ have a rapid growth and form gel containing more nonevaporating water.

Table 5 indicated that $\mathrm{CH}$ content of group C and L2 pastes increased as hydration degree increased gradually, whereas that of the pastes containing fly ash decreased. From our previous analysis, it can been seen that the nonevaporating water of pastes $\mathrm{C}$ and the pastes containing fly ash increased greatly while that of pastes L2 tended to be stable. Since limestone powder primarily played the filling role, the content of $\mathrm{CH}$ consumed by fly ash in the two reactions was larger than that produced by the cement hydration. Thus, the nonevaporating water of C-S-H gel was much higher. The CH content of group R2 was significantly less than that of group L2 and obviously decreased further in group G2, which is consistent with the $\mathrm{XRD}$ results (i.e., remind us very briefly of what XRD says). The phenomenon indicated that grinding stimulated pozzolanic activity of fly ash effectively. With the content of limestone powder increase and cement content decrease, hydration product $\mathrm{CH}$ is from cement so that the $\mathrm{CH}$ content decreases for $\mathrm{L} 4$ and $\mathrm{L} 6$ samples. The $\mathrm{CH}$ content decreases with hydration age (because of the decrease of cement) and limestone content. As for R4, raw fly ash content is $40 \%$ which would decrease the hydration product $\mathrm{CH}$. Otherwise, as the secondary hydration between fly ash and $\mathrm{CH}$, the pozzolanic activity of raw fly ash is not as good as ground fly ash; the values of sample G4 were so low.

3.3.2. Morphology of Hydration Products. As shown in Figure 11, at $28 \mathrm{~d}$, a large number of fibrous C-S-H gels grew as clusters of radiation and overlapped in group C. The microstructure of the pastes containing raw fly ash was 

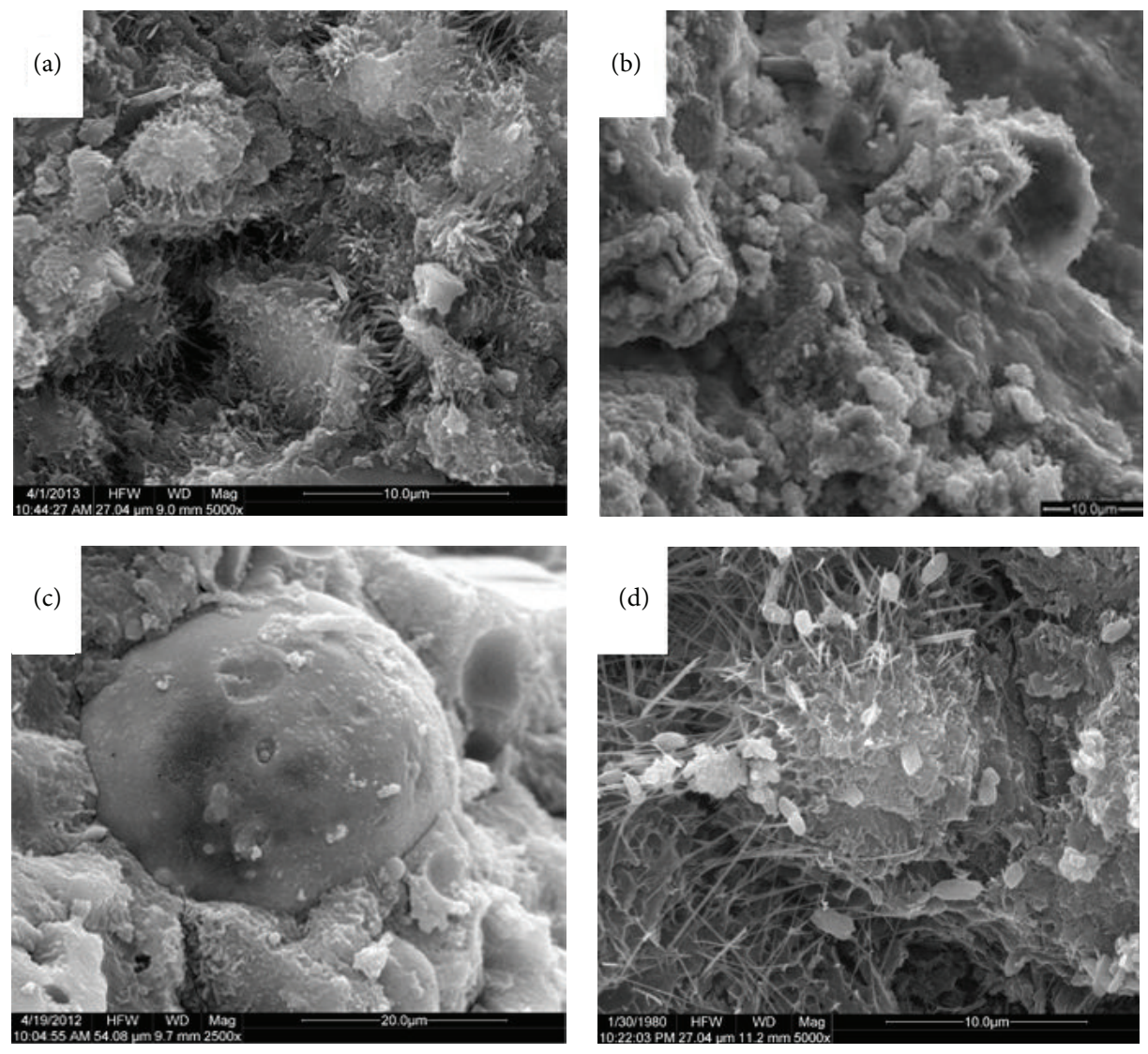

FIGURE 11: Microstructure of hydration products of (a) C, (b) L2, (c) R2, and (d) G2 at $28 \mathrm{~d}$.

loose and the particle surface was substantially smooth. The clubbed C-S-H gel and irregular gel as growing hydration products attached to the particles can be observed. The observation means that fly ash mainly played the role of filling at an early stage of hydration. A large number of C$\mathrm{S}-\mathrm{H}$ gels were produced in group $\mathrm{G} 2$ and made the structure denser. The main hydration products of group $\mathrm{L} 2$ were $\mathrm{CH}$, ettringite crystal, and C-S-H gel of type II netlike and type III granular; at that time, limestone powder particles were already wrapped by a lot of dense gel.

$\mathrm{C}-\mathrm{S}-\mathrm{H}$ gel and thin layered $\mathrm{CH}$ staggered (see Figure 12); hence the structure was denser in group $\mathrm{C}$ at $90 \mathrm{~d}$. Moreover, a large amount of layered $\mathrm{CH}$ could be observed in group R2; fly ash particles were wrapped in lots of hydration products, which showed that fly ash had been involved in the hydration limitedly. This is basically the same as group G2, but the C$\mathrm{S}$-H gel which wrapped the fly ash particles at the later stage was denser. It could also be observed that the surface of the limestone powder particle had been eroded and the structure of the reaction product was relatively denser, indicating that the limestone powder had taken part in the hydration process.

Due to the thick ash, the surface of the glass beads was substantially smooth at the age of $28 \mathrm{~d}$ (see Figure 13). Also it was observed that increased hydration products presented in the surroundings and are attached to the surface of the structure that were relatively loose, illustrating that the fly ash primarily acted as microaggregate filler. The fly ash particles appeared as etching and a dense layer of hydration products covered their surfaces at the age of $90 \mathrm{~d}$. Again, a large amount of tufted C-S-H became very compact and dense and grew to intermingle with a laminar sheet of $\mathrm{CH}$ forming denser microstructure dense. Although the pozzolanic reaction of fly ash had been clearly evident, the consumption of $\mathrm{CH}$ was not much and the flaky $\mathrm{CH}$ crystals were still abound. Even in the slurry sample with up to $60 \%$ of fly ash, a large number of laminated growth of $\mathrm{CH}$ crystals existed next to the fly ash particles with a considerable degree of reaction. This observation indicated that the consumption of $\mathrm{CH}$ in fly ash reaction was small, where more of the $\mathrm{CH}$ crystals were still in the slurry cementitious material with high volume of fly ash to maintain the internal alkaline slurry at a higher level.

\section{Conclusions}

The results from this study support the following.

The strength of mortar decreased with increasing limestone powder content. The water-binder ratio had little influence on the development rule of the strength of mortar containing limestone powder. Limestone powder mainly played roles in promoting cement hydration and it hardly participated in hydration reaction. However, at the later period (90 d), limestone powder showed weak chemical activity. It may react with $\mathrm{C}_{3} \mathrm{~A}$ to generate monocarboaluminates. 

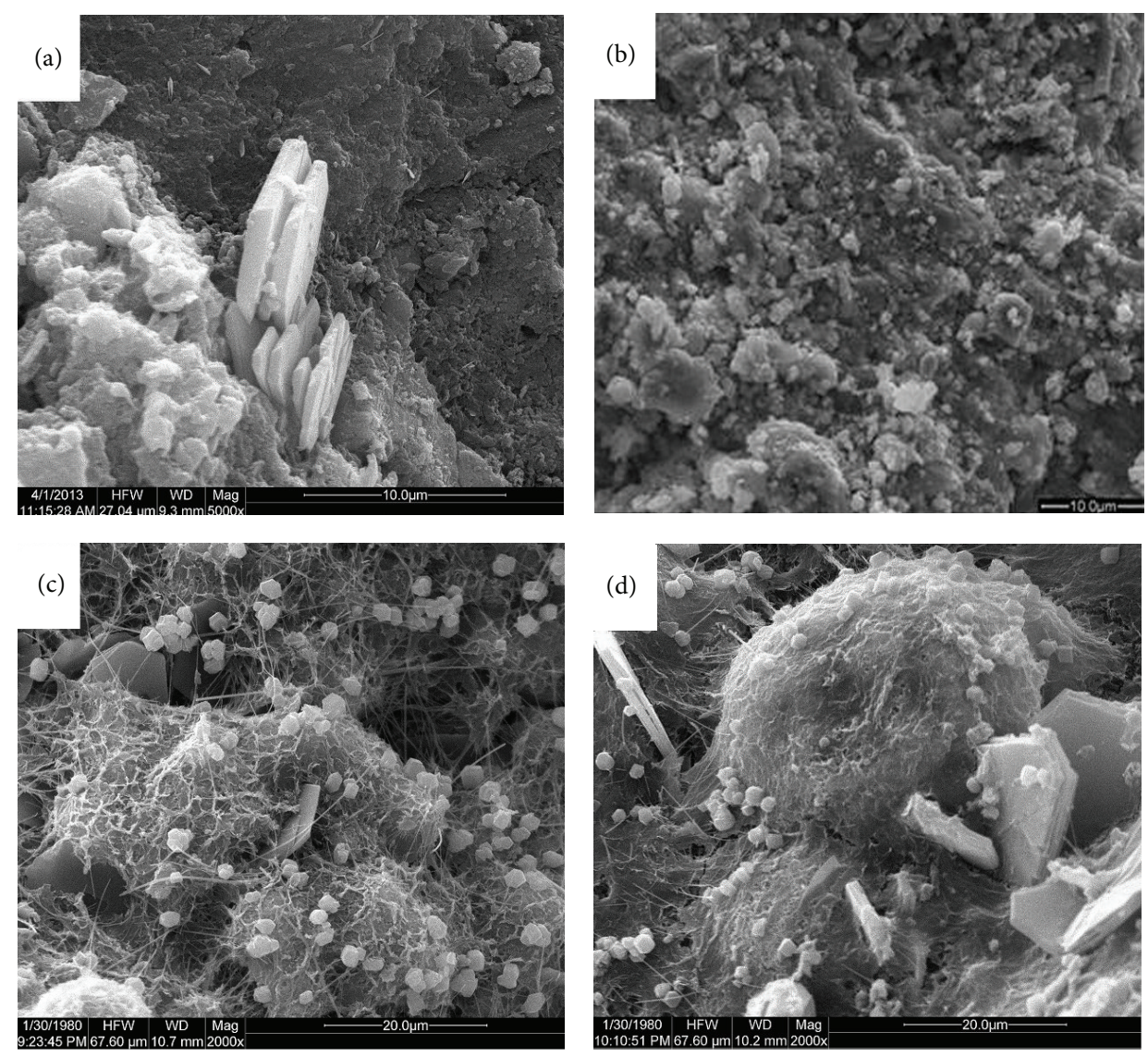

Figure 12: Microstructure of hydration products of (a) C, (b) L2, (c) R2, and (d) G2 at 90 d.
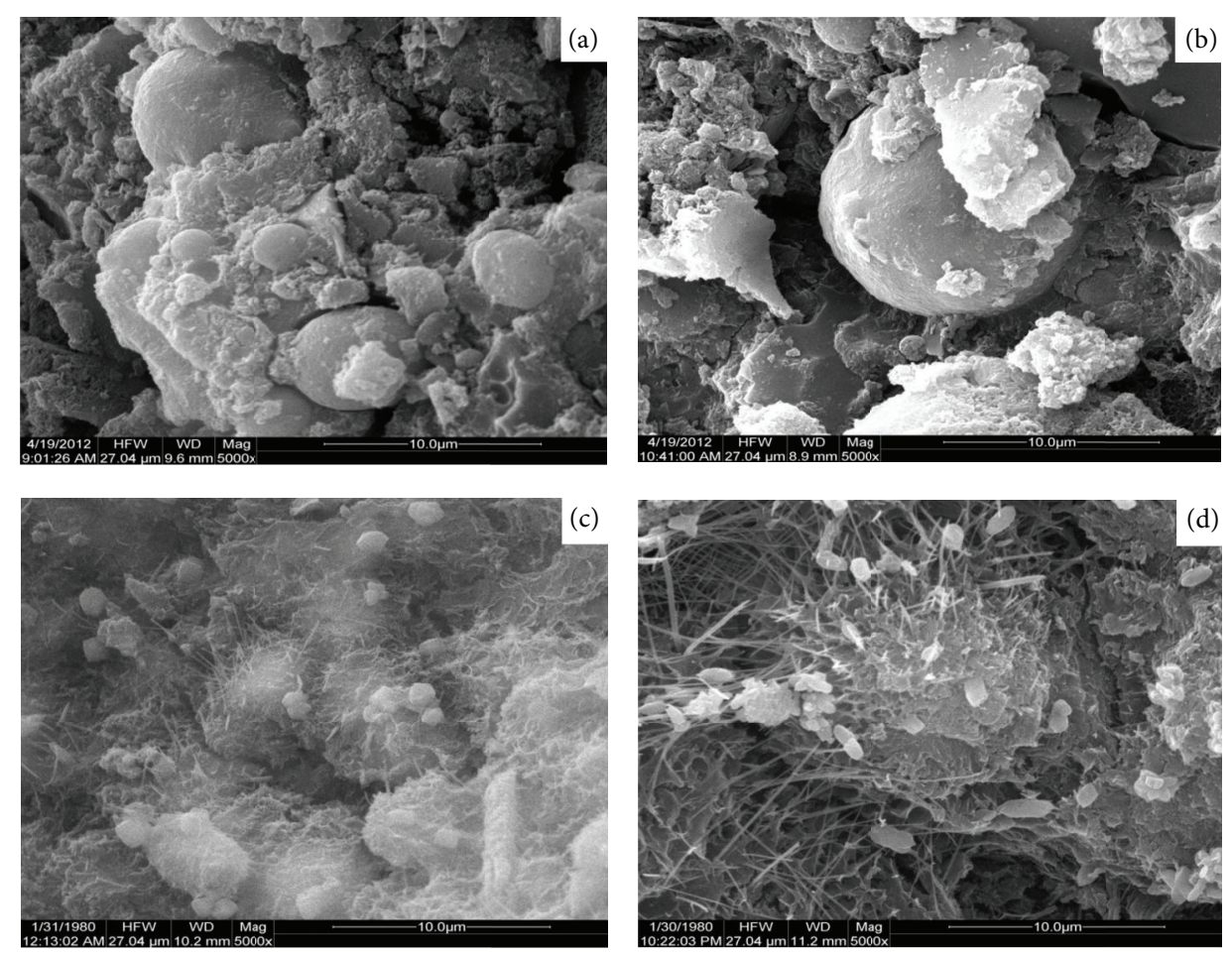

Figure 13: Microstructure of hydration products of ((a) and (b)) R6 and G6 at 28 days and ((c) and (d)) R6 and G6 at 90 d. 
Compared with limestone powder, low quality fly ash may improve the mechanical properties of cement-based materials and ameliorate the hydration and microstructure. In addition, low quality fly ash showed better mechanical property at a low water-binder ratio. The early hydration heat of the binder containing low quality fly ash was lower than that of the binder containing limestone powder.

Grinding did not only affect the physical properties but also improve the hydration of fly ash in cement-based materials. At the early age, the activity of low quality fly ash was low; but, at the later stage, it exhibits improvements, especially after grinding. Furthermore, low quality fly ash delayed the induction period, shortened the accelerator period, and hence had little effect on the second exothermic peak.

\section{Competing Interests}

The authors declare that they have no competing interests.

\section{Acknowledgments}

This material is based upon work supported by the Central Nonprofit Scientific Research Fund for Institutes (no. CKSF2016003/CL); National Natural Science Foundation of China (51208391 and 51139001), China Postdoctoral Science Foundation (no. 2015M582213) and National Basic Research Program of China (973 Program, 2013CB035901).

\section{References}

[1] P. K. Mehta, "Reducing the environmental impact of concrete," Concrete International, vol. 23, no. 1, pp. 61-67, 2001.

[2] E. Worrell, L. Price, N. Martin, C. Hendriks, and L. O. Meida, "Carbon dioxide emissions from the global cement industry," Annual Review of Energy and the Environment, vol. 26, pp. 303329, 2001.

[3] S. H. Liu and P. Y. Yan, "Effect of limestone powder on microstructure of concrete," Journal Wuhan University of Technology, Materials Science Edition, vol. 25, no. 2, pp. 328-331, 2010.

[4] S. H. Liu, P. Y. Yan, and J. W. Feng, "Effect of limestone powder and fly ash on magnesium sulfate resistance of mortar," Journal of Wuhan University of Technology (Material Science Edition), vol. 25, no. 4, pp. 700-703, 2010.

[5] D. Zorić, D. Lazar, O. Rudić, M. Radeka, J. Ranogajec, and H. Hiršenberger, "Thermal conductivity of lightweight aggregate based on coal fly ash," Journal of Thermal Analysis and Calorimetry, vol. 110, no. 1, pp. 489-495, 2012.

[6] T. Zhang, Q. Yu, J. Wei, P. Zhang, and P. Chen, "Improvement of surface cementitious properties of coarse fly ash by dehydration and rehydration processes," Journal of Thermal Analysis and Calorimetry, vol. 109, no. 1, pp. 265-271, 2012.

[7] A.-M. Poppe and G. De Schutter, "Cement hydration in the presence of high filler contents," Cement and Concrete Research, vol. 35, no. 12, pp. 2290-2299, 2005.

[8] V. Rahhal and R. Talero, "Early hydration of portland cement with crystalline mineral additions," Cement and Concrete Research, vol. 35, no. 7, pp. 1285-1291, 2005.

[9] K. A. Paine, L. Zheng, and R. K. Dhir, "Experimental study and modelling of heat evolution of blended cements," Advances in Cement Research, vol. 17, no. 3, pp. 121-132, 2005.
[10] P. Lawrence, M. Cyr, and E. Ringot, "Mineral admixtures in mortars: effect of inert materials on short-term hydration," Cement and Concrete Research, vol. 33, no. 12, pp. 1939-1947, 2003.

[11] P. Y. Yan and Q. H. Zhang, "Influence of active or inert mineral admixtures on the hydration properties of composite cementitious materials," Journal of Railway Science and Engineering, vol. 4, no. 1, pp. 1-7, 2007.

[12] P. Yan and Q. Zhang, "Microstructural characteristics of complex binder paste containing active or inert mineral admixtures," Journal of the Chinese Ceramic Society, vol. 34, no. 12, pp. 1491-1496, 2006.

[13] W. Wongkeo, P. Thongsanitgarn, P. Chindaprasirt, and A. Chaipanich, "Thermogravimetry of ternary cement blends: effect of different curing methods," Journal of Thermal Analysis and Calorimetry, vol. 113, no. 3, pp. 1079-1090, 2013.

[14] J. Baron and C. Douvre, "Technical and economical aspects of the use of limestone filler additions in cement," World Cement, vol. 18, no. 3, pp. 100-104, 1987.

[15] M. Heikal, H. El-Didamony, and M. S. Morsy, "Limestone-filled pozzolanic cement," Cement and Concrete Research, vol. 30, no. 11, pp. 1827-1834, 2000.

[16] B. Lothenbach, G. Le Saout, E. Gallucci, and K. Scrivener, "Influence of limestone on the hydration of Portland cements," Cement and Concrete Research, vol. 38, no. 6, pp. 848-860, 2008.

[17] X. T. Huang and Z. J. Han, "Research and application of influence of man-made sand powder on the properties of concrete," Hydroelectric Engineering, vol. 49, no. 1, pp. 32-35, 1995.

[18] X.-G. Li, "Use of man-made sand with high content stone powder in concrete," Journal of Building Materials, vol. 7, no. 1, pp. 66-71, 2004.

[19] M. K. Zhou, S. M. Peng, and J. Xu, "Effect of stone powder on stone chippings concrete," Journal of Wuhan University of Technology (Material Science Edition), vol. 11, no. 2, pp. 328-331, 1996.

[20] S. H. Liu and K. H. Fang, "Review on comprehensive utilization of fly ash," Fujian Building Materials, vol. 37, no. 2, pp. 8-9, 2008.

[21] Y. Xi, "Present status and prospects of fly ash in comprehensive utilization," China Resources Comprehensive Utilization, vol. 27, no. 3, pp. 15-18, 2009.

[22] G. Ye, X. Liu, G. De Schutter, A.-M. Poppe, and L. Taerwe, "Influence of limestone powder used as filler in SCC on hydration and microstructure of cement pastes," Cement and Concrete Composites, vol. 29, no. 2, pp. 94-102, 2007. 

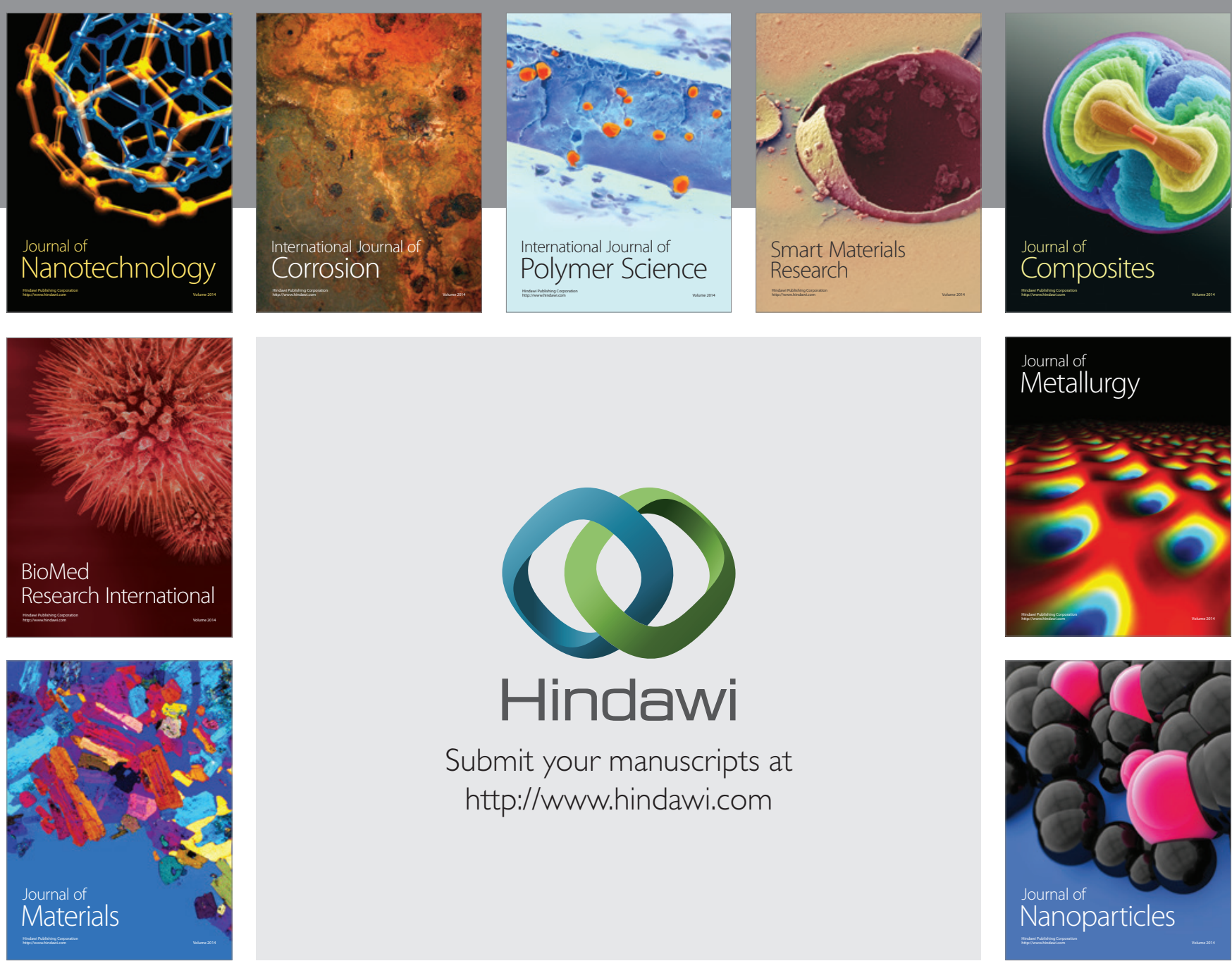

\section{Hindawi}

Submit your manuscripts at

http://www.hindawi.com

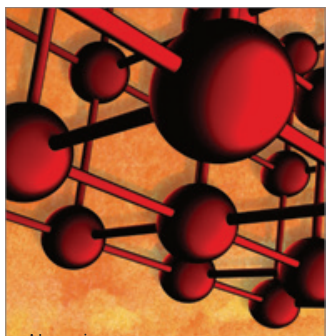

Materials Science and Engineering
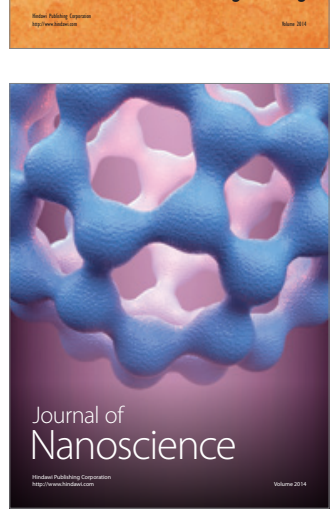
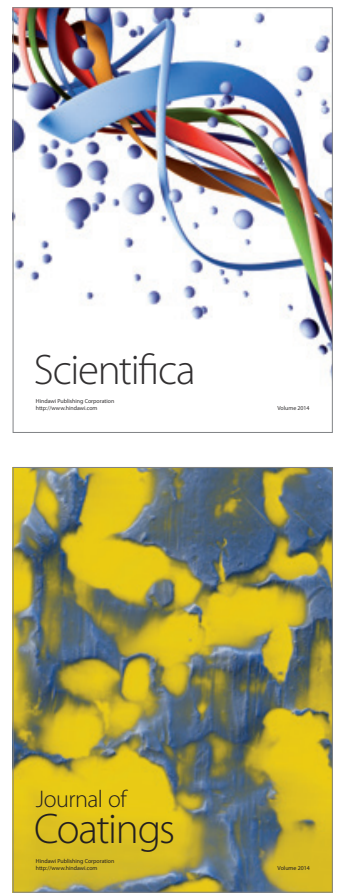
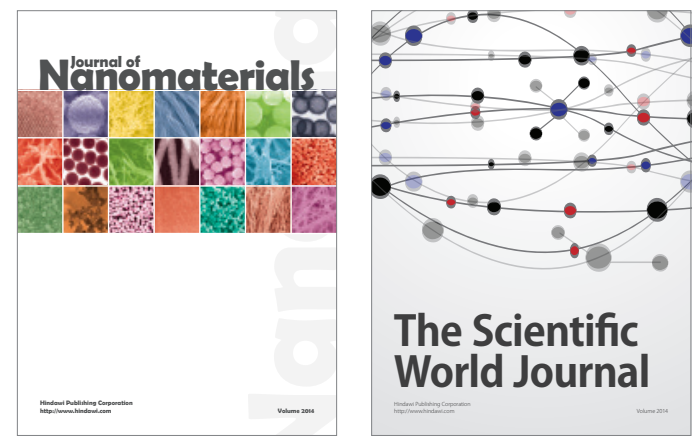

The Scientific World Journal
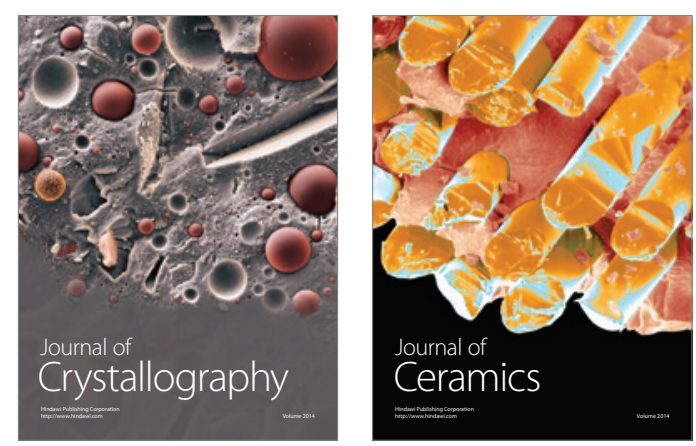
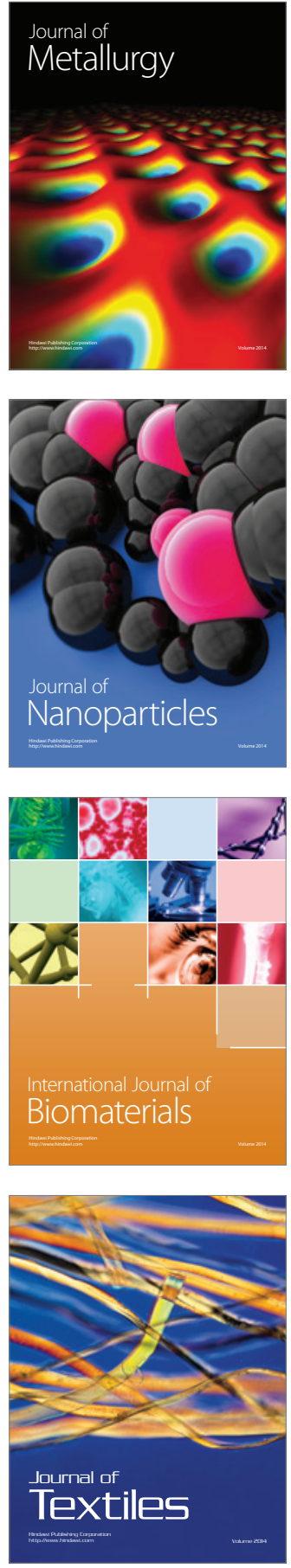